\title{
O triste visionário: Lima Barreto e seu tempo
}

[ The sad visionary: Lima Barreto and his time

\section{Caion Meneguello Natal ${ }^{\mathbf{I}}$}

SCHWARCZ, Lilia Moritz. Lima Barreto: triste visionário. São Paulo: Cia. das Letras, 2017.

Ao reconstruir minuciosamente a trajetória familiar, social e intelectual de

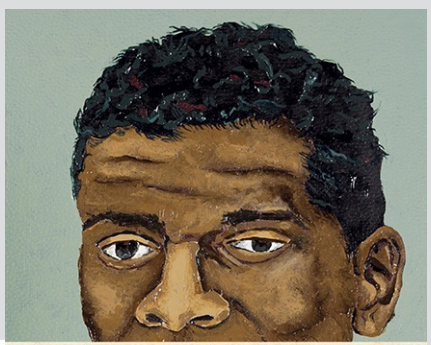

Afonso Henrique de Lima Barreto, Lilia Moritz Schwarcz, em seu mais recente livro, não se furta em apresentar, também nos detalhes, o contexto histórico e as tensões sociopolíticas vigentes na capital brasileira em período que ficou conhecido como República Velha. Ao relato biográfico, a autora articula com maestria um mapa fino dos principais eventos e problemas que afetaram o

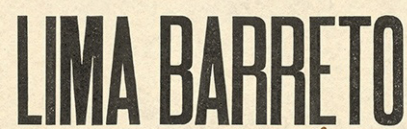
TRISTE VISIONÁRIO

LIILIA MOIRITZ SCHWAIRCZ

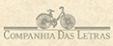

Civilista, e tantos mais.

NATAL, Caion Meneguello. O triste visionário: Lima Barreto e seu tempo. Revista do Instituto de Estudos Brasileiros, Brasil, n. 68, p. 235-240, dez. 2017.

DOI: http://dx.doi.org/Io.II6o6/issn.23I6-90IX.voi68p235-240

I Universidade de São Paulo (USP, São Paulo, SP, Brasil). nascente, e precário, regime republicano no Brasil. À medida que a vida de Lima vai sendo deslindada, são explicados os acontecimentos que marcaram a turbulenta implantação da República no país, como a Abolição da Escravidão, proclamação do novo regime, Revolta da Armada, Canudos, Revolta da Vacina, Remodelação do Rio de Janeiro, Campanha 
Com efeito, não se trata de simples desfile de acontecimentos, senão que a autora, ciosa de seu ofício, examina as questões candentes desse período, como a discriminação contra a população negra e mestiça, as iniquidades sociais, o elitismo na política, custeado pela economia cafeeira, as teorias raciais, as ações de saneamento e modernização urbana, as mudanças nos costumes, as arengas literárias, os movimentos, tensões e conflitos sociais etc., além de projetos de civilização e identidade nacional que vigoraram no alvorecer do século XX.

Neto de escravos, Afonso Henriques de Lima Barreto nasceu numa casa modesta, no bairro das Laranjeiras, na rua Ipiranga número I8, em I3 de maio de I88I. Sua mãe, Amália Augusta, era professora primária e diretora. O pai, João Henriques, formou-se e trabalhou como tipógrafo até fins da década de I880, em jornais cariocas famosos, como Jornal do Commercio e A Reforma. Lima teve três irmãos: o mais velho, Carlindo, e os mais novos, Evangelina e Eliézer.

A biografia de Lima Barreto é a árdua travessia de um mestiço alfabetizado de classe média que colidiu o tempo todo contra os racismos operantes na sociedade brasileira da época. O Lima delineado por Lilia Schwarcz é o personagem-testemunha em que estão sintomatizados os referenciais de classificação daquele momento, que eram, principalmente, os preconceitos de cor, classe e origem social. Embora a escravidão tivesse terminado oficialmente, seu legado ainda se fazia efetivo na estruturação das hierarquias, códigos e condutas sociais. E a vida de Lima Barreto nos mostra como essa herança era (e ainda permanece) coletiva, obstando a consolidação da cidadania prometida pelo regime republicano. Escritor militante, em sua literatura e crônicas jornalísticas, Lima jamais se absteve de denunciar "as mazelas da escravidão no Brasil, os mecanismos de humilhação, bem como as diversas formas de racismo por aqui vigentes" (p. 26).

Em tal contexto, raça era demarcador de desigualdades, de submissão e de prestígio, de obediência e de mando, capaz de naturalizar diferenças e legitimar um sistema de poder paternalista, exclusivista e racista. Para dar suporte aos marcadores raciais, entretanto, era preciso mais que a práxis e a tradição. Fazia-se necessário um conjunto de discursos que pudessem subscrever-lhes um cariz "científico". E o que não faltava nesse período eram teorias para justificar o racismo. Conhecidas como deterministas, tais teorias pregavam que entre brancos, negros, índios e mestiços 
haveria diferenças biológicas insuperáveis, naturais e hereditárias. O branco seria a raça pura, superior, mais inteligente e disposta ao progresso material, enquanto as demais, o negro e o mestiço, sobretudo, seriam raças inferiores, estariam num estágio ainda primitivo de evolução e desenvolvimento mental. Ainda segundo essas teorias, as populações negras e mestiças, em razão de sua genética deficiente, estariam mais propensas à criminalidade, a sofrer de demência, tuberculose e epilepsia. Associavam-se tais ocorrências às populações afrodescendentes por conta de uma suposta determinação racial/hereditária.

O saber determinista, em suas várias facetas, chegava aos trópicos via autores como Cesare Lombroso, Ernst Haeckel, Arthur de Gobineau, Hippolyte Taine, Georges de Lapouge e Herbert Spencer, cujas obras influenciaram intelectuais brasileiros de renome, como Nina Rodrigues, Silvio Romero, Euclides da Cunha e Oliveira Vianna. Em finais do século XIX, a mestiçagem era considerada o mal por excelência a atravancar o desenvolvimento do país. Surgiam nessa época as teses eugenistas que defendiam a imigração de brancos europeus como forma de branquear a população. Supunha-se que somente com esse branqueamento o Brasil poderia se desenvolver economicamente e ter consolidadas em seu território as instituições democrático-liberais. Assim, enquanto houvesse negros e mestiços, o tão almejado progresso não se completaria. Pobreza, doença e criminalidade seriam, pois, efeitos da mistura das raças e da degeneração que essa mistura significava.

Em dezembro de I887, a mãe de Lima, Amália, faleceu de tuberculose. Desde a década anterior, o pai, João Henriques, vinha sofrendo surtos psicóticos. Como a tuberculose e a loucura eram entendidas como males hereditários, signos de degeneração, e associadas aos setores afrodescendentes, essas experiências familiares pareciam ratificar o pensamento determinista. Desde a infância, portanto, Lima via-se assombrado pelo estigma racial que colava às populações de pele morena o selo da demência e de outras enfermidades (tuberculose, sífilis, epilepsia etc.). Em março de I89o, João Henriques deixou o emprego de tipógrafo e partiu com a família para a Ilha do Governador, onde iria trabalhar como administrador das Colônias de Alienados. Então, o ainda menino Lima Barreto passava a maior parte do tempo na Ilha, convivendo com os internos do manicômio. O futuro escritor começava a ver de perto o rosto da loucura.

Em I897, Lima iniciou seus estudos em engenharia civil na Politécnica do Rio de Janeiro. Em I903, nosso biografado abandonou a escola e, aprovado em concurso público, assumiu o cargo de amanuense na Secretaria da Guerra. Em I909, o jovem escritor viu a publicação de seu primeiro trabalho literário: Recordações do escrivão Isaías Caminha. O livro é uma crítica ao conservadorismo e à frivolidade dos jornais que circulavam no Rio naquele momento. Narra a história do jovem Isaías, afrodescendente que vem para a cidade grande com vistas a tornar-se "doutor". Busca o ofício de jornalista e consegue o cargo pretendido em um grande jornal: estabelece-se na redação de $O$ Globo. No entanto, Isaías tem seus sonhos frustrados ao deparar-se com o preconceito e a humilhação. Narrado em primeira pessoa, Recordações sumariza eventos da vida íntima do autor em meio a personagens e fatos de sua rotina profissional de jornalista e amanuense. Além disso, a obra enfoca temas delicados, e caros a Lima, como as desigualdades sociais e os preconceitos de cor, 
raça, ou classe. A tonalidade autobiográfica do romance é acentuada: o personagem principal desloca-se do subúrbio para ganhar a vida como jornalista, de pouco sucesso, diga-se, no centro da cidade; é pobre, mas inteligente e bem formado, e possui "uma tez de cor pronunciadamente azeitonada" (p. 2I2). Nutria muitos sonhos, mas frustrava-se diante da hipocrisia, da vaidade aristocrática e do hermetismo vigentes nos círculos intelectuais da metrópole.

Em I9I5, vem a público o romance Numa e a ninfa. Novamente, a ficção coloca-se a serviço da crítica social. Dessa vez, o alvo principal são os políticos, definidos como "cauda de bajuladores", e a política no Brasil, "ritual de salamaleques e falsas demonstrações de amizade” (p. 244). A fatura autobiográfica, irônica e crítica, prevalece em Triste fim de Policarpo Quaresma, livro lançado ao final de I9I5. A narrativa referencia os tempos de infância de Lima Barreto, vividos na Ilha do Governador. O romance centra-se no personagem Policarpo Quaresma, o qual pretende estabelecer o tupi-guarani como língua nacional e é avesso às inovações vindas do estrangeiro. Leitor assíduo de livros nacionais e patriota inveterado, vive a pensar soluções para o Brasil. Policarpo decide, então, fazer um ofício e endereçá-lo ao ministro do Interior propondo a introdução do tupi como idioma oficial. $\mathrm{O}$ documento é publicado nos jornais e vira motivo de piada. Por conta da vergonha, Policarpo acaba no hospício.

Como frisa Schwarcz, Policarpo é representação do pai de Lima Barreto. Da mesma forma que o personagem fictício, João Henriques escrevera artigos sobre a Ilha do Governador nos quais enaltecia as terras férteis do Brasil, defendendo a tese de que a agricultura seria uma vocação natural do país. Tal qual Henriques, Policarpo compra e se muda para um sítio. Ambos enlouquecem. Policarpo pratica a agricultura, pois a considera dádiva dos trópicos. Porém, em outro paralelo flagrante com a Ilha do Governador, as formigas não param de invadir a propriedade e comprometer a lavoura. Triste fim é obra amargurada, pessimista. Poli-carpo significa o que produz muitos frutos, mas Policarpo Quaresma morre sem legar nada, nem herança, nem herdeiro. Seu sítio é invadido pelas formigas, que simbolizam os inimigos do país, os que destroem os sonhos e as possibilidades de melhorias. Aqui, a demência figura associada ao fracasso do ideal de uma sociedade próspera e equânime, onde as benesses do progresso poderiam, de fato, servir a todos.

O último romance que Lima Barreto publicou foi Vida e morte de M. J. Gonzaga de Sá, em I9I9. O livro narra as andanças e desilusões de Gonzaga de Sá, um amanuense que cultiva o hábito de perambular pelas ruas do Rio de Janeiro a questionar a sociedade e lamentar o tédio de sua profissão. Qualquer semelhança com o cotidiano do escritor não é mera coincidência. Ele ainda teria tempo para ver publicada sua coletânea de contos Histórias e sonhos, lançada em fins de I920.

Lima teve intensa atuação como cronista. Publicou em diversos noticiosos, como Correio da Noite, Correio da Manhã, Gazeta da Tarde, O Copacabana, e nas revistas Ordem e Progresso, Revista Americana, A Epoca, Illustração Brasileira, A Voz do Trabalhador, entre outros. Criticava políticos, instituições, escritores famosos, costumes etc., não economizando no escárnio, no deboche, na ironia. As referências literárias mais caras a Lima Barreto eram as obras de Dostoiévski, Flaubert, Balzac, Dickens, Maupassant, Eça de Queirós e Tolstói. A escolha do realismo respondia à preocupação 
de denunciar as instituições burguesas e as injustiças sociais. Em seus artigos jornalísticos e textos de ficção, o autor sempre se pautava por uma escrita militante. Principalmente nas crônicas, usava o termo bovarismo (baseado na personagem Madame Bovary, de Flaubert) para ridicularizar a mania que as elites brasileiras tinham de pensar ser (e viver) o que não eram, isto é, de adotar um modus vivendi “importado". Em especial, Lima desferia ataques aos modelos de comportamento e consumo francês e norte-americano - cinema, teatro, música, cafés, piqueniques, futebol, regatas, vestuário, arquitetura, vogas literárias e filosóficas etc.

Desde meados dos anos I9Io, o vício em bebidas alcoólicas vinha se acentuando. Por suas bebedeiras, Lima Barreto passou dois meses internado no Hospital Nacional de Alienados - de agosto a outubro de I9I4. Na época, costumava-se associar moléstias mentais a alcoolismo. Assim, o criador de Policarpo Quaresma incorporava o papel que o preconceito racial tentava impor aos afrodescendentes e que ele mesmo gostaria de ver abolido: o de um ser humano cuja herança biológica o destinaria à alienação. Em dezembro de I9I9, Lima foi internado pela segunda vez no Hospício Nacional, permanecendo até fevereiro de I920. Nessa ocasião, começou a escrever o romance $O$ cemitério dos vivos, que ficou inacabado e seria publicado postumamente (a primeira edição data de I953). A história inspira-se em seu Diário do hospício, caderno em que registrou as experiências no manicômio. Por complicações decorrentes do alcoolismo, Lima Barreto faleceu em sua residência a Iํ de novembro de I922.

O trabalho de Lilia Schwarcz é admirável. A autora faz da biografia um estudo historiográfico e sociológico em que a vida e a obra do biografado tornam-se constitutivas das questões, valores e eventos que marcaram o espaço-tempo em análise. Se o livro de Lilia se expõe a ressalvas, é muito mais pelo excesso teórico com que se detém em certos pontos, mas jamais pela insuficiência da abordagem. Parece que nada escapa ao olhar percuciente da autora. Por outro lado, temos a impressão de que não necessitaria gastar tanta tinta com alguns assuntos, como as demoradas explicações a respeito da instauração da República, da Revolta da Armada e da relação platônica que Lima estabelecia com Machado de Assis. Alguns capítulos poderiam ser resumidos em poucas páginas, a exemplo do capítulo 7, sobre a revista Floreal, e o capítulo I3, sobre os pendores anarquistas de Barreto. Também é de se perguntar por que o modernismo paulista entra com tamanho vulto lá pelo final do livro. De qualquer modo, não se trata aqui de condenar essas passagens, que, longe de preteríveis, poderiam ter sido tecidas de modo mais sucinto.

Há que se notar, enfim, a sensibilidade da autora para seu tempo presente, pois o livro ora lançado vem problematizar conflitos que continuam a afligir nossa experiência de brasileiros, tais como preconceito racial, bloqueio político e econômico incidindo sobre a maior parte da população, desigualdade, associação naturalizada entre pobreza, doença e pigmentação da pele etc. 
SOBRE O AUTOR

CAION MENEGUELLO NATAL é doutor em História pela Universidade Estadual de Campinas (Unicamp) e pesquisador pós-doutorando no Instituto de Estudos Brasileiros da Universidade de São Paulo (IEB/USP). E-mail: caionnatal@hotmail.com 